\title{
Selected aspects of dielectric behavior of plasma sprayed titanates
}

\author{
Pavel CTIBOR $^{\mathrm{a}, *}$, Josef SEDLACEK ${ }^{\mathrm{b}}$ \\ ${ }^{a}$ Institute of Plasma Physics, ASCR, v.v.i., Za Slovankou 3, Prague, Czech Republic \\ ${ }^{b}$ Department of Electrotechnology, Faculty of Electrical Engineering, Czech Technical University, \\ Technicka 2, Prague, Czech Republic
}

Received March 1, 2011; Revised March 15, 2011; Accepted March 19, 2011

(C) The Author(s) 2012. This article is published with open access at Springerlink.com

\begin{abstract}
XRD measurements were carried out on plasma sprayed titanates $\mathrm{BaTiO}_{3}, \mathrm{CaTiO}_{3}, \mathrm{MgTiO}_{3}$ and a mixture of the last two. Samples were tested as dielectrics and volume resistivities of the materials were also summarized. Microwave microscopy was used for mapping of the dielectric response of selected samples. The results show differences in the crystal structure between plasma sprayed coatings and feedstock powders in the case of $\mathrm{BaTiO}_{3}$ and $\mathrm{MgTiO}_{3}$ whereas $\mathrm{CaTiO}_{3}$ is crystalograffically identical with its feedstock. The reason can be found in larger sensitivity of $\mathrm{BaTiO}_{3}$ and $\mathrm{MgTiO}_{3}$ to the reductive conditions at plasma spraying whereas $\mathrm{CaTiO}_{3}$ seems to be rather inert from this viewpoint. However $\mathrm{CaTiO}_{3}$ exhibits anomalous dielectric losses because of intrinsic conductivity.
\end{abstract}

Key words: plasma spraying; dielectric properties; electrical properties; $\mathrm{BaTiO}_{3}$ and titanates; capacitors

\section{Introduction}

Synthetic perovskite $\mathrm{CaTiO}_{3}(\mathrm{CT})$, geikielite $\mathrm{MgTiO}_{3}$ (MT) and their mixture $\mathrm{MgTiO}_{3}-\mathrm{CaTiO}_{3}$ (MCT) are materials well known and widely used as dielectrics in a sintered state. CT is high-permittivity linear dielectric material whose structure is not influenced by plasma spraying - neither chemical nor phase composition, as demonstrated earlier [1]. MT belongs to the family of low-loss microwave dielectrics and MT-CT solution is known by its temperature stability of permittivity. Namely the composition $\left(\mathrm{Mg}_{0.95} \mathrm{Ca}_{0.05}\right) \mathrm{TiO}_{3}$ is used in connection with this feature.

\footnotetext{
* Corresponding author.

E-mail: ctibor@ipp.cas.cz
}

In recent decades plasma spraying has become a well accepted technology as the coating method for metallic and ceramic materials and has been used in a variety of fields including electrical engineering. The coatings have lamellar character of a body formed with porosity aligned with respect to the lamellas. Spraying does not require heating of the substrate to the melting point of the deposited material.

Often the research is focused on the microstructure of plasma sprayed coatings and features like porosity, unmelted particles, cracks and residual stress. Above listed characteristics are responsible for the behavior of coatings. However in the case of titanates phenomena taking place on atomic level and single crystal cell level are also important. Raman spectroscopy, infrared spectroscopy and near-field microwave microscopy are suitable techniques for this characterization. 
$\mathrm{Ca}$ and $\mathrm{Mg}$ have the same charge but different ionic radii $\left(r_{\mathrm{Ca}^{2+}}=0.134 \mathrm{~nm}\right.$ and $\left.r_{\mathrm{Mg}^{2+}}=0.103 \mathrm{~nm}\right)$ [2]. A mixture of CT and MT melts and forms an eutectic liquid at $1462{ }^{\circ} \mathrm{C}$, which, under proper solidification conditions, can be used to achieve a highly dense product. During processing presence of intermediate phases of $\mathrm{MgTi}_{2} \mathrm{O}_{5}$ and $\mathrm{Mg}_{2} \mathrm{TiO}_{4}$ was noted, and they were difficult to eliminate completely from the reaction products [3-5].

MCT exhibits differences from MT in the metal-oxygen bond lengths which are relevant to the stability of the compounds. While the infrared and Raman spectra of CT and MT have been measured [2-7], other cations at the $A$ and/or $B$ sites alter the vibrational properties of $A B \mathrm{O}_{3}$ studied by these spectroscopic techniques. This encourages the authors to measure the Raman and infrared spectra. In the plasma sprayed MCT we have earlier recognized $\mathrm{MgTi}_{2} \mathrm{O}_{5}$ and $\mathrm{Mg}_{2} \mathrm{TiO}_{4}$ phases [1].

Besides the mentioned dielectric titanate materials, we have sprayed also one representative of ferroelectrics - barium titanate. $\mathrm{BaTiO}_{3}$ (BT) is an interesting multifunctional oxide that exhibits complex phase appearance. Between $120{ }^{\circ} \mathrm{C} \quad(393 \mathrm{~K})$ and $1457{ }^{\circ} \mathrm{C}(1730 \mathrm{~K}), \mathrm{BaTiO}_{3}$ has a cubic perovskite structure that consists of corner linked oxygen octahedra containing $\mathrm{Ti}^{4+}$, with $\mathrm{Ba}^{2+}$. Cooling below $120{ }^{\circ} \mathrm{C}$ results in small displacements in the positions of the cations in the unit cell resulting in polar ferroelectric phase existing in the temperature interval between $5{ }^{\circ} \mathrm{C}(278 \mathrm{~K})$ and $120{ }^{\circ} \mathrm{C}$ [8].

$\mathrm{BaTiO}_{3}$, due to its high dielectric constant, is used frequently as multilayer capacitor components and sensors. However, it has been found that, with respect to the electrical properties, $\mathrm{BaTiO}_{3}$ in the form of thin-films does not reach the qualities of bulk material. This difference was explained by a combination of the intrinsic dead layer effect, a stress effect, an effect of the microstructure within the thin film, and an effect of the stoichiometry [9]. In particular, the relative permittivity of films decreases when the film thickness is reduced [10]. The optimal dielectric characteristics are obtained for sintered $\mathrm{BaTiO}_{3}$-based sample with bulk density of about $5300 \mathrm{~kg} \cdot \mathrm{m}^{-3}$ [11]. Any deviation from the stoichiometric $\mathrm{Ba} / \mathrm{Ti}$ ratio leads to suppression of the high relative permittivity of the ferroelectric barium titanate [12]. To detect the tetragonal $\mathrm{BaTiO}_{3}$ phase by X-ray diffraction, the split of peaks of (002) and (200) reflection is a well-established indication [13-15].

In general there are differences of the behavior of barium titanate in the form of a single-crystal, sintered bulk material and thin film $[8,12]$. Plasma spraying enables to create layers with 'bulk-like' thickness but adhering on a metallic substrate of various shapes. Free-standing parts of titanate ceramics can be fabricated as well by plasma spraying [16]. $\mathrm{BaTiO}_{3}$ itself was up to now seldom plasma sprayed and the understanding of its behavior in the form of sprayed coating is not satisfactory. For coatings with the thickness of about $100 \mu \mathrm{m}$ the values of relative permittivity 50 and loss factor 0.08 were reported [17]. The dielectric properties of the plasma sprayed $\mathrm{BaTiO}_{3}$ were related to the degree of crystallinity [17]. The coatings containing more crystalline material have higher relative permittivity. The relative permittivity was affected also by cracks and splat interfaces within the coating [17]. The reported value of relative permittivity is however surprisingly low, because one and more orders higher values are typical for bulk $\mathrm{BaTiO}_{3}[18]$.

The focus of this paper is to report selected aspects of the dielectric characteristics of the as-sprayed barium titanate coatings and compare it with other plasma sprayed titanates.

\section{Experimental}

\subsection{Feedstock materials}

All materials were obtained in the form of tablets of industrial purity, produced by the sintering of micropowders. The sintering was carried out by companies Epsilon (Librice, Czech Republic) Ceramic Capacitors Ltd. (Hradec Kralove, Czech Rep.) and Teceram (Hradec Kralove, Czech Rep.).

The synthetic form of perovskite $\mathrm{CaTiO}_{3}$ was produced by reactive sintering of $\mathrm{CaO}$ and $\mathrm{TiO}_{2}$. $\mathrm{CaTiO}_{3}$ powder used for experiments was sintered without any additives (like $\mathrm{ZnO}$ ), normally used for decreasing the sintering temperature. Tablets were crushed and sieved into powder of the correct size for spraying. $\mathrm{MgTiO}_{3}$ and $\mathrm{MCT}$ were sintered using $\mathrm{MgO}$, $\mathrm{CaCO}_{3}$ and $\mathrm{TiO}_{2}$. After sieving, the size distribution of the feedstocks was 63-125 microns for all three materials.

$\mathrm{BaTiO}_{3}$ feedstock powder was obtained by crushing and sieving sintered coarse agglomerates. Those 
agglomerates were prepared by a reactive sintering of micrometer-sized powder of $\mathrm{BaCO}_{3}$ and $\mathrm{TiO}_{2}$ used as starting materials. After sieving, the size distribution of the BT feedstock for spraying was 20 and $63 \mu \mathrm{m}$ with an average at $40 \mu \mathrm{m}$, whereas the bulk density measured by helium pycnometry was $5721 \mathrm{~kg} \cdot \mathrm{m}^{-3}$.

\subsection{Plasma spraying}

The CT, MT and MCT samples were manufactured using a high throughput Water-Stabilized Plasma (WSP) spray system WSP500 ${ }^{\circledR}$ at Institute of Plasma Physics (Prague, Czech Republic) at ambient atmosphere. The WSP system operates at about $160 \mathrm{~kW}$ arc power and can process high amounts of material. This system can be used to fabricate deposits similar but not identical to those prepared by means of conventional atmospheric plasma-spray systems based on gas-stabilized torches. As substrates flat carbon steel coupons (Euronorm S355) were used whereas the powder was fed in by compressed air through two injectors. Just before spraying, the steel was grit blasted with $\mathrm{Al}_{2} \mathrm{O}_{3}$ with a mean diameter of $650 \mu \mathrm{m}$. The deposited thickness was about $1.5 \mathrm{~mm}$ for self-supporting deposits. Thick deposits were stripped from the substrate by a releasing agent or by thermal cycling between +200 and $-70{ }^{\circ} \mathrm{C}$.

To manufacture BT samples, a Gas-Stabilized Plasma gun (GPS) was used to perform Atmospheric Plasma Spraying (APS) process. The conventional d.c. GPS gun F4 consisted of a thoriated tungsten cathode of $10 \mathrm{~mm}$ in diameter with a conical tip and a copper anode/nozzle. The plasma gas mixture used was argon/hydrogen with the total flow rate $60 \mathrm{slm}$. The powder was injected perpendicularly to the plasma jet axis with argon as a carrier gas (at constant flow rate $5 \mathrm{slm}$ at pressure $0.3 \mathrm{MPa}$ for all spray experiments) through an injector located $3 \mathrm{~mm}$ downstream (called external injection) of the torch nozzle exit. The system can process 1 to $5 \mathrm{~kg} / \mathrm{h}$ of a ceramic powder. Barium titanate was sprayed at arc power around $30 \mathrm{~kW}$. Spray distance was $100 \mathrm{~mm}$ and plasma spraying deposition time was about 5 min to reach the thickness from 0.9 to $1 \mathrm{~mm}$. Substrates, rectangular shaped $\left(120 \times 20 \mathrm{~mm}^{2}\right)$ $3 \mathrm{~mm}$ thick, were made of carbon steel (Euronorm S355). Just before spraying, they were grit blasted with $\mathrm{Al}_{2} \mathrm{O}_{3}$ with a mean diameter of $400 \mu \mathrm{m}$. The substrates were disposed on a rotating sample holder whose diameter was $90 \mathrm{~mm}$. This substrate holder was rotated (tangential speed of $1 \mathrm{~m} / \mathrm{s}$ ) with a horizontal axis and simultaneously translated back and forth orthogonally to the plasma jet axis at a velocity of $24 \mathrm{~mm} / \mathrm{s}$, with an excursion of $160 \mathrm{~mm}$, the plasma torch being stationary.

\subsection{Characterization techniques}

$\mathrm{X}$-ray diffraction (XRD) was performed as a phase identification with SIEMENS D500 ${ }^{\mathrm{TM}}$ and SIEMENS D5000 ${ }^{\mathrm{TM}}$ equipment allowed identifying phases present within powders and coatings. For estimation of the crystallinity of the plasma sprayed BT coating relative peak areas have been used. These have been calculated from relative ratios of the areas of the three main peaks $(101,111$ and 200) from the tetragonal titanate phase.

Microwave microscope Agilent AFM 5400 was used for simultaneous monitoring of the surface profile by AFM and dielectric response on external field applied at resonant frequency (approx. 2.6 MHz). This relatively new technique-near-field scanning microwave microscopy (SMM) permits characterization of the effects of inhomogeneities and defects in crystals, films, and compacts on the local dielectric behavior. By moving the tip/cavity assembly over a surface, one can map the microwave cavity resonant frequency $f_{\mathrm{r}}$ and quality factor $Q$ as a function of position and generate images of the sample. In addition to qualitative images, the microscope can provide quantitative characterization of local dielectric properties [19].

The complex dielectric permittivity of $\mathrm{CT}$ was studied in the $440 \mathrm{~Hz}-1 \mathrm{MHz}$ frequency range and $10-270 \mathrm{~K}$ temperature interval using HP 4192A impedance analyzer with a Leybold He-flow cryostat (operating range $5-300 \mathrm{~K}$ ). The impedance of the cylindrical sample with Au electrodes sputtered on the cylinder ends was recorded on cooling rate of $2 \mathrm{~K} / \mathrm{min}$.

All other electric measurements were performed at room temperature. The deposits were stripped off from the substrates. The surfaces were ground after spraying to eliminate surface roughness. A thin layer of aluminum as the electrode was sputtered in a reduced pressure on the ground surface [1]. A three-electrode system was used with a guarded electrode, whereas an unguarded electrode was sputtered on the entire surface of the sample opposite side. The electric field was applied parallel with the spraying direction (i.e., perpendicular to the substrate surface). Capacity was measured in the frequency range from $120 \mathrm{~Hz}$ to 
$1 \mathrm{MHz}$ using the impedance analyzer 4284A (Agilent, CA, USA). Applied voltage was $1 \mathrm{~V}$ AC whereas the stabilized electric source was equipped with a micrometric capacitor type 16451A (Agilent, CA, USA). Relative permittivity $\varepsilon_{\mathrm{r}}$ was calculated from measured capacities $C_{\mathrm{P}}$ and specimen dimensions (Eq. (1))

$$
C_{\mathrm{P}}=\varepsilon_{0} \varepsilon_{\mathrm{r}}(1 / k)
$$

where $\varepsilon_{0}=8.854 \times 10^{-14} \mathrm{~F} \cdot \mathrm{cm}^{-1} ; 1 / k[\mathrm{~cm}]$ is defined as the ratio between the guarded surface and the thickness of the sample [20].

This same arrangement and equipment was used for the loss factor measurement at the same frequencies as capacity.

Electric resistance was measured with a special resistivity adapter - Keithley model 6105. The electric field was applied from a regulated high-voltage source and the values read by a multi-purpose electrometer (617C, Keithley Instruments, USA). The magnitude of the applied voltage was $100 \pm 2 \mathrm{~V}$ DC. Volume resistivity was calculated from the measured resistance and specimen dimensions. Typically 4 - 5 specimens were measured and the average calculated.

\section{Results}

\subsection{Phase composition}

According to X-ray diffraction measurement of CT coating, the phase composition is the same as in the feedstock powder - pure $\mathrm{CaTiO}_{3}$ (PDF2 card No. 00-022-0153). The XRD pattern of MT coating is very similar to the XRD pattern of MCT coating (see Fig. 1). The original meta-titanate $\mathrm{MgTiO}_{3}$ is partly decomposed during the spray process onto $\mathrm{Mg}_{2} \mathrm{TiO}_{4}$ and $\mathrm{MgTi}_{2} \mathrm{O}_{5}$. All these components are present also in MCT coating (see Fig. 1), whereas in addition $\mathrm{CaTiO}_{3}$ is present as an individual phase.

The XRD pattern of BT (see Fig. 2), corresponds strictly to the tetragonal phase (PDF2 card No. 01-081-2204), which was confirmed to be the constituent of the feedstock powder as well as of the coating. Intensity ratio of individual peaks of the feedstock as well as of the coating is very similar to patterns reported in the literature [21]. In the coating, certain quantity of amorphous phase is present, manifested itself by a halo centered on $28^{\circ} 2 \theta$ in the pattern [22], and quantified as $10 \%$.

In spite of $\mathrm{MgTi}_{2} \mathrm{O}_{5}$ and $\mathrm{Mg}_{2} \mathrm{TiO}_{4}$ origin during the spraying, as confirmed by XRD [1], only two phases with different relative permittivities were detected by scanning microwave microscopy, see Fig. 3, similarly as in [3]. Permittivities of $\mathrm{MgTi}_{2} \mathrm{O}_{5}, \mathrm{Mg}_{2} \mathrm{TiO}_{4}$ and $\mathrm{MT}$ are very similar and very different from CT. Figure 3 is a superposition of the AFM contact mode image (roughness) and scanning microwave microscopy capacitance mode image (colors). The image is artificially coloured - blue and red zones represent different relative permittivities.

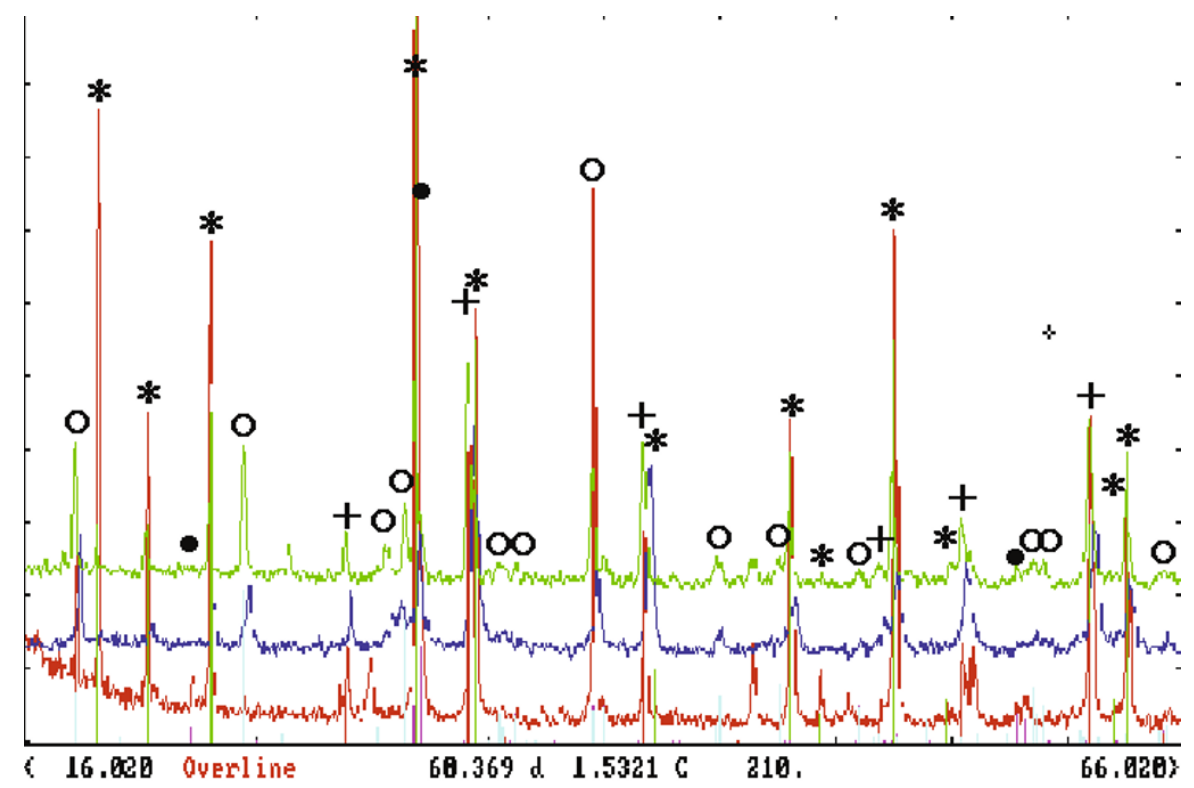

Fig. 1 XRD phase analysis of MCT. Patterns (from the bottom): feedstock powder; plasma sprayed coating; freeflight particles. Indicated phases: $\mathrm{MgTiO}_{3}$ - asterisk; $\mathrm{Mg}_{2} \mathrm{TiO}_{4}$ - cross; $\mathrm{MgTi}_{2} \mathrm{O}_{5}$ - open circle; $\mathrm{CaTiO}_{3}-$ full circle 




Fig. 2 XRD pattern of plasma sprayed BT coating

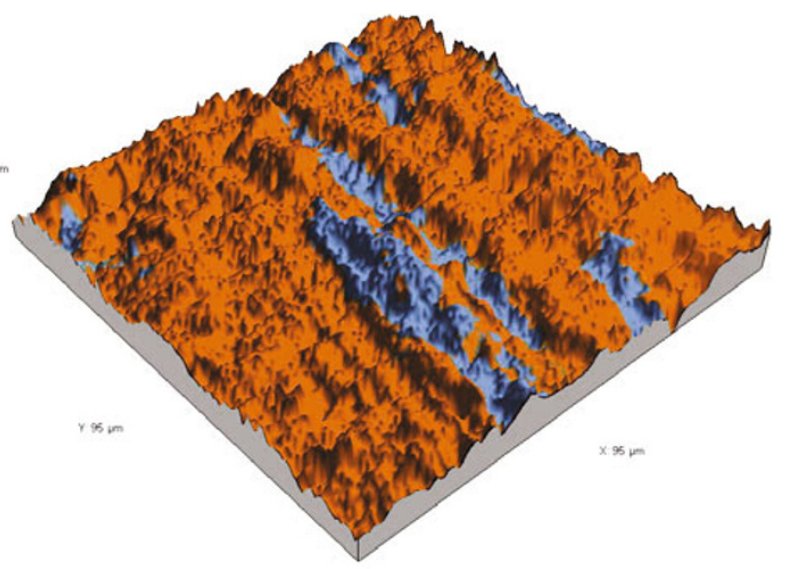

(a)

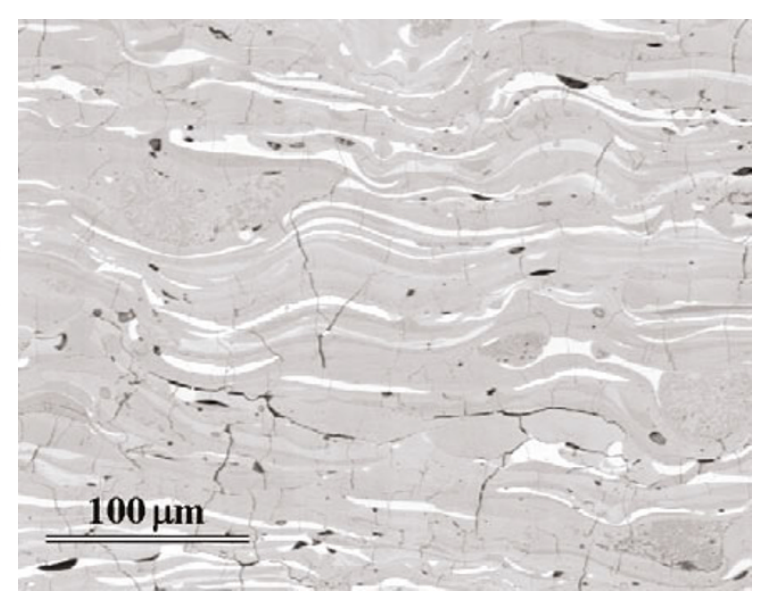

(b)

Fig. 3 Scanning microwave microscopy image of MCT as-sprayed surface (artificially colored - blue and red zones represent different relative permittivities). Image (b) is SEM-BE image showing the lamellar microstructure

$\mathrm{CT}$ (perovskite) is a high permittivity material $\varepsilon_{\mathrm{r}}^{\prime}=170$ [23], $\mathrm{MgTiO}_{3}$ (giekielite) has a low $\varepsilon_{\mathrm{r}}{ }^{\prime}=17$ [24] and $\mathrm{Mg}_{2} \mathrm{TiO}_{4}$ (qandilite) also has even lower $\varepsilon_{\mathrm{r}}{ }^{\prime}=12$ [25]. However SMM setup is not able to distinguish well the last two phases [26], also in Fig. 3a the blue lamellas correspond to CT and the red background to all other phases.

\subsection{Dielectric measurements}

Dielectric properties of plasma sprayed $\mathrm{CaTiO}_{3}$ between $10 \mathrm{~K}$ and room temperature are displayed on Figs. 4 - 6. The incipient ferroelectricity of CT $[27,28]$ is suppressed in the case of plasma sprayed coatings, see Fig. 4. Rather relaxor type of behavior takes place. Relaxor features are believed to be connected with a situation when more than one type of ions occupies

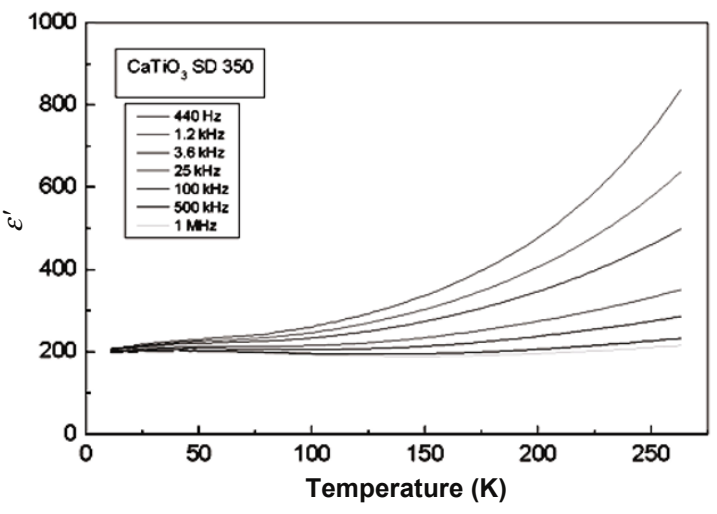

Fig. 4 Real part of permittivity of plasma sprayed $\mathrm{CaTiO}_{3}$ between $10 \mathrm{~K}$ and room temperature 
equivalent crystallographic position. One of the most important features of relaxors is their low frequency dispersion at maximum dielectric permittivity. The other features of this include dependence of phase transition temperature on the method of its determination. The origin of such properties is probably connected with a presence of microscopic polar regions (nano-domains) in these materials [29]. With temperature falling down also the $\varepsilon^{\prime \prime}$ values decrease to minimum (for a given frequency), cf. Fig. 5 .

In the studied frequency range, the relative permittivity of all specimens exhibits significant ionic relaxation process [30]. Strong relaxation effect is shown by the $\varepsilon_{\mathrm{r}}^{\prime}$ reduction with the operating frequency, see Fig. 7. In Ti-based materials, the concentrations of intrinsic defects are determined by oxygen partial pressure and, additionally, variations in defect concentrations can be detected by conductivity measurements. At low oxygen partial pressures, the

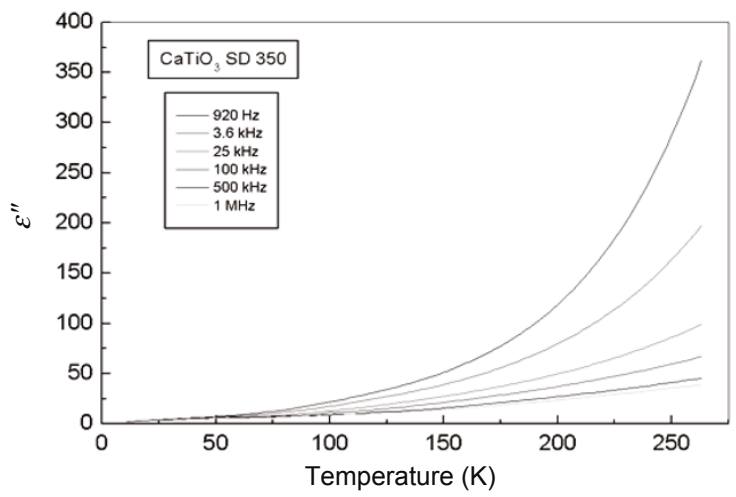

Fig. 5 Imaginary part of permittivity of plasma sprayed $\mathrm{CaTiO}_{3}$ between $10 \mathrm{~K}$ and room temperature



Fig. 6 Loss tangent of plasma sprayed $\mathrm{CaTiO}_{3}$ between $10 \mathrm{~K}$ and room temperature materials show n-type conduction with oxygen vacancy as the dominant defect while at high oxygen partial pressures the materials show p-type conduction with the cation vacancy as the dominant defect. For different materials, the transition from n-type conduction to p-type conduction occurs at different oxygen partial pressures [31]. The partial pressure of oxygen required to reduce for example $\mathrm{TiO}_{2}$ to $\mathrm{Ti}_{2} \mathrm{O}_{3}$, $\mathrm{Ti}_{3} \mathrm{O}_{5}$ or $\mathrm{Ti}_{4} \mathrm{O}_{7}$ is of the order of $10^{-5} \mathrm{~Pa}$ at around $2000{ }^{\circ} \mathrm{C}$, while during plasma spraying in the air, oxygen partial pressure does not go below $1 \mathrm{~Pa}$ [32]. Dielectric losses of our titanate samples, namely BT and CT are however high (see Fig. 8). Electric conductivity is responsible for it with dominating contribution of dc-conductivity component. The $\varepsilon^{\prime \prime}$

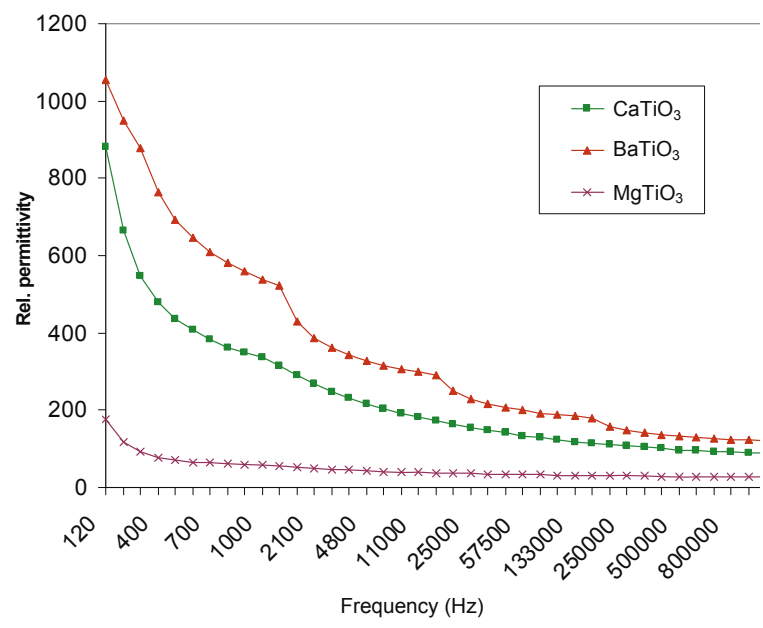

Fig. 7 Frequency dependence of the relative permittivity of plasma sprayed $\mathrm{BaTiO}_{3}, \mathrm{CaTiO}_{3}$, and $\mathrm{MgTiO}_{3}$ at room temperature

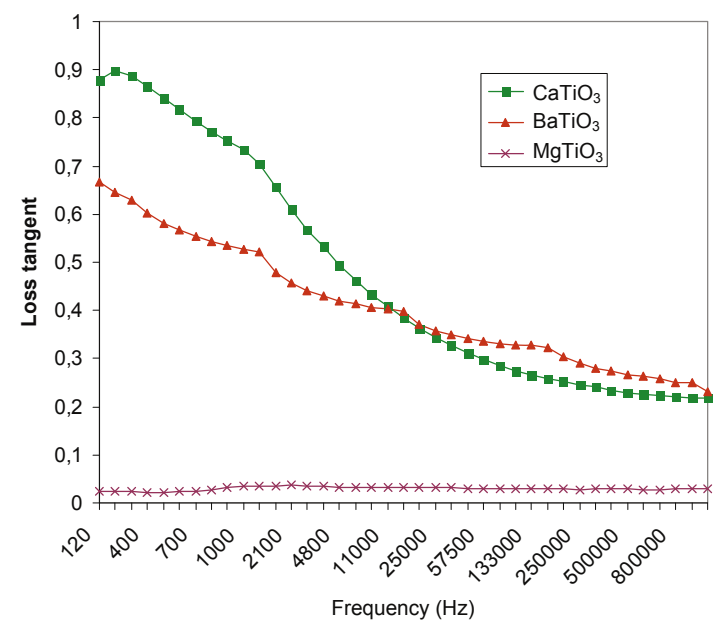

Fig. 8 Frequency dependence of the loss tangent of plasma sprayed $\mathrm{BaTiO}_{3}, \mathrm{CaTiO}_{3}$, and $\mathrm{MgTiO}_{3}$ at room temperature 
dependence can be treated as typical for materials with dc-conductivity which dominates over relaxation processes [33].

Table 1 shows the volume resistivity and Fig. 9 corresponding conductivity of plasma sprayed and sintered BT, CT, MT and MCT materials. We see the different values with typically several orders of magnitude lower resistivity values for plasma sprayed specimen compared to sintered materials.

\subsection{Scanning microwave microscopy}

Scanning microwave microscopy images of BT are given in Figs. 10 and 11. AFM images represent surface roughness. Since the surface was materialografically polished, the subtle changes in the roughness are associated with various phases. These phases are concentrated predominantly in individual lamellas, cf. MCT SEM micrograph in the Fig. 3b. In the case of BT, the difference between lamellas is mainly in terms of $\mathrm{Ba} / \mathrm{Ti}$ ratio [39]. Such a feature is, as expectable, more easily visible on cross sections (see Fig. 11), then on in-plane (i.e. spray direction) sections (see Fig. 10). The lamellas red and yellow on capacitance mode images are more Ti-rich (higher permittivity) whereas blue areas are Ba-rich (lower permittivity). The Ba-rich phase has slightly lower hardness (hardness measured by us: $\mathrm{BaTiO}_{3}$ is about 6.5 GPa versus $\mathrm{TiO}_{2}$ about $11.0 \mathrm{GPa}$; $\mathrm{BaO}$ not reported as a layer). The Ba-rich phase is darker on AFM contact mode image, since it is more easily worn-out by polishing process. These "steps" on border of lamellas are about $80 \mathrm{~nm}$ high (also see Fig. 12), whose height is consistent with observations made by SEM.

\section{Conclusions}

$\mathrm{BaTiO}_{3}, \mathrm{CaTiO}_{3}, \mathrm{MgTiO}_{3}$ and a mixture of the last two materials with $5 \mathrm{wt} \%$ of $\mathrm{CaTiO}_{3}$ in $\mathrm{MgTiO}_{3}$ were plasma sprayed by two complementary spray techniques. Volume dc-resistivities of the materials were summarized. Microwave microscopy was used for mapping of the dielectric response of selected samples whereas conventional dielectric testing on macro-scale was carried out too.

$\mathrm{CaTiO}_{3}$ exhibits anomalous dielectric losses because of intrinsic conductivity. Relaxor type of behavior takes place at dielectric measurements, whereas

Table 1 Volume resistivity of studied materials ( $\mathrm{P}$ - plasma sprayed, $\mathrm{S}-$ sintered)

\begin{tabular}{ccccccccc}
\hline Sample & BT $(\mathrm{P})$ & BT $(\mathrm{S})$ & CT $(\mathrm{P})$ & CT $(\mathrm{S})$ & MT $(\mathrm{P})$ & MT $(\mathrm{S})$ & MCT $(\mathrm{P})$ & MCT $(\mathrm{S})$ \\
\hline$P(\Omega \mathrm{m})$ & $6.08 \times 10^{4}$ & $2.42 \times 10^{9}$ & $7.51 \times 10^{9}$ & $1.41 \times 10^{12}$ & $1.15 \times 10^{8}$ & $6.90 \times 10^{11}$ & $1.17 \times 10^{7}$ & $7.54 \times 10^{11}$ \\
\hline
\end{tabular}

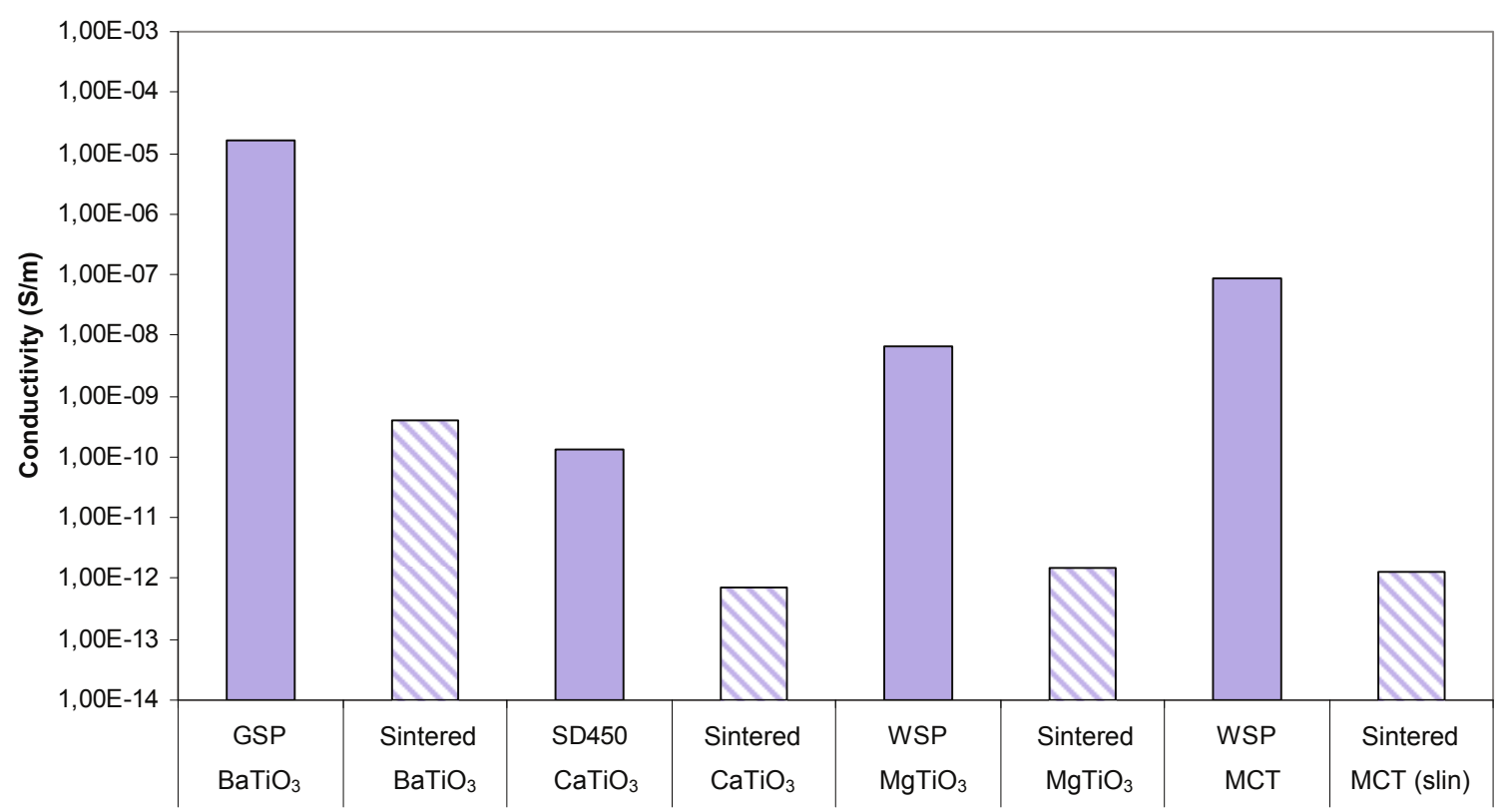

Fig. 9 Conductivity of plasma sprayed and sintered BT, CT, MT and MCT 


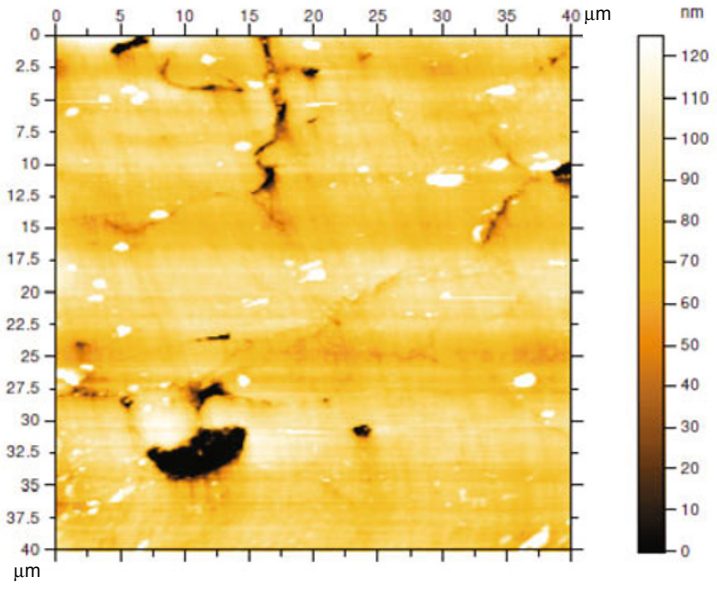

(a)

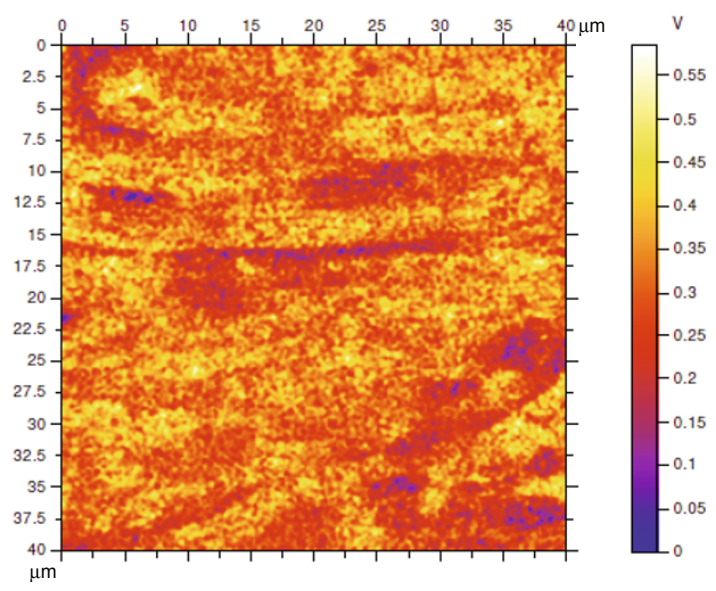

(b)

Fig. 10 AFM contact mode image of $\mathrm{BaTiO}_{3}$ (in plane orientation). (a) Roughness representation: peaks are lighter and valleys darker (black color represents pores). (b) Scanning microwave microscopy image of $\mathrm{BaTiO}_{3}$ (in plane orientation) - artificially colored: blue and red zones represent different relative permittivities

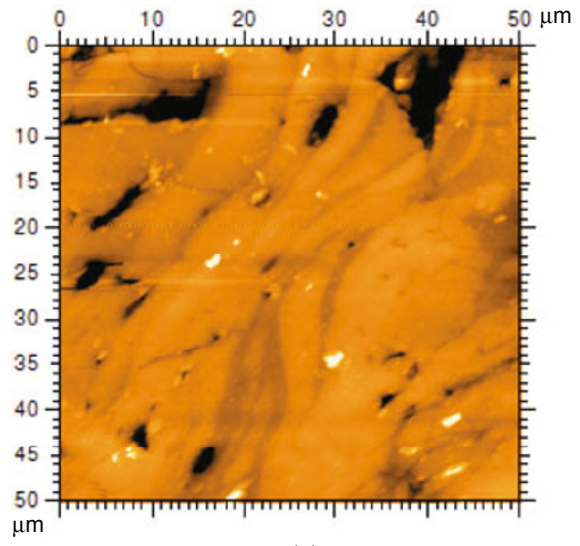

(a)

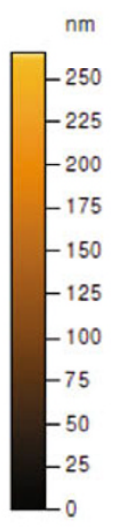

Fig. 11 AFM contact mode image of $\mathrm{BaTiO}_{3}$ (cross sectional orientation). (a) Roughness representation: peaks are lighter and valleys darker (black color represents pores). (b) Scanning microwave microscopy image of $\mathrm{BaTiO}_{3}$ (cross sectional orientation) - artificially colored: blue and red zones represent different relative permittivities

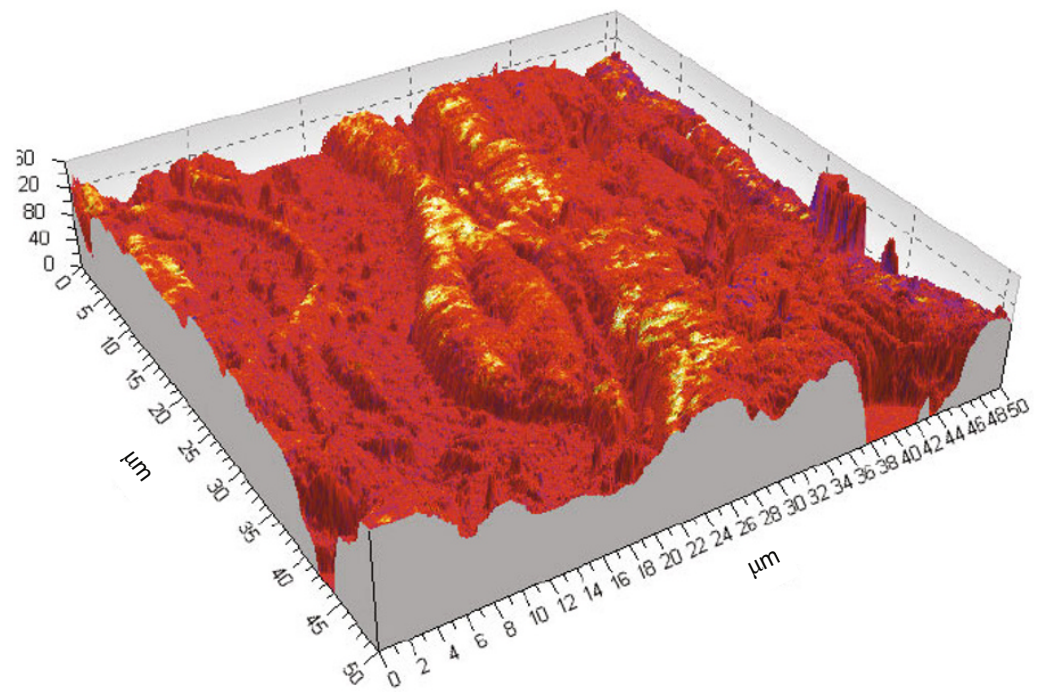

Fig. 12 Superposition of the AFM contact mode image and SMM image - $\mathrm{BaTiO}_{3}$ cross section 
dc-conductivity is responsible for the high dielectric losses. All coatings are slightly oxygen deficient however under detection limits of XRD materials - the color of all of them was darker compared to sintered samples.

Polarization of grain boundaries combined with n-type conduction with oxygen vacancy as the dominant defect contributes to the observed pseudo-relaxor response of $\mathrm{BaTiO}_{3}$ and $\mathrm{CaTiO}_{3}$ to $\mathrm{AC}$ electric field. $\mathrm{MgTiO}_{3}$ as a low-loss material has the above mentioned effects slightly suppressed and more similar to sintered bulk [1]. Plasma spraying of applicable ceramic dielectrics capable of substituting bulk parts will need further research. In the other hand plasma spraying with its possibility to cover all materials, having variable shapes and sizes, with thick coatings offers a promising way for future development.

Open Access This article is distributed under the terms of the Creative Commons Attribution License which permits any use, distribution, and reproduction in any medium, provided the original author(s) and source are credited.

\section{Acknowledgment}

The authors thank to J. Dubsky (IPP ASCR) for XRD measurements, to M. Savinov (Inst. of Physics ASCR) for the temperature measurement of dielectric properties of $\mathrm{CaTiO}_{3}$. Scanning microwave microscopy was done by M. Fenner (Agilent, Germany). $\mathrm{BaTiO}_{3}$ was sprayed at University of Limoges, France. This work was supported by the Czech Science Foundation (No. P205/11/2311).

\section{References}

[1] Ctibor P, Sedlacek J, Neufuss K, Chraska P. Ceramics International 2003, 29: 955-960.

[2] Hirata T, Ishioka K, Kitajima M. Journal of solid state chemistry 1996, 124: 353-359.

[3] Zhang Q, McGinn PJ. Journal of the American Ceramic Society 2006, 89: 3817-3823.

[4] Zheng H, Csete de Gyorgyfalva GDC, Quimby R, Bagshaw H, Ubic R, Reaney IM, Yarwood J. Journal of the European Ceramic Society 2003, 23: 2653-2659.

[5] Huang C-L, Pan C-L, Shium S-J. Materials Chemistry and Physics 2002, 78: 111-115.
[6] Jiang Y, Guo R, Bhalla AS. J Phys Chem Solids 1998, 59: 611-615.

[7] Cavalcante LS, Marques VS, Sczancoski JC, Escote MT, Joya MR, Varela JA, Santos MRMC, Pizani PS, Longo E. Chemical Engineering Journal 2008, 143: 299-307.

[8] Boutinaud P, Tomasella E, Ennajdaoui A, Mahiou R. Thin Solid Films 2006, 515: 2316-2321.

[9] Zhao MH, Bonnell DA, Vohs JM. Effect of ferroelectric polarization on the adsorption and reaction of ethanol on $\mathrm{BaTiO}_{3}$. Surface Science 2008, 602: 2849-2855.

[10] Setter N, Waser R. Electroceramic materials. Acta Materialia 2000, 48: 151-178.

[11] Jin HZ, Zhu J, Ehrhart P, Fitsilis F, Jia CL, Regnery $\mathrm{S}$, Urban K, Waser R. An interfacial defect layer observed at $(\mathrm{Ba}, \mathrm{Sr}) \mathrm{TiO}_{3}-\mathrm{Pt}$ interface. Thin Solid Films 2003, 429: 282-285.

[12] Mitic VV, Mitrovic I. The influence of $\mathrm{Nb}_{2} \mathrm{O}_{5}$ on $\mathrm{BaTiO}_{3}$ ceramics dielectric properties. Journal of the European Ceramic Society 2001, 21: 2693-2696.

[13] Waser R. Modeling of electroceramics, applications and prospects. Journal of the European Ceramic Society 1999, 19, 655-664.

[14] Yu P, Cui B, Chany Z. Preparation and characterization of Ag-doped $\mathrm{BaTiO}_{3}$ based X7R ceramics. Materials Research Bulletin 2009, 44: 893-897.

[15] Simon-Seveyrat L, Hajjaji A, Emziane Y, Guiffard B, Guyomar D. Re-investigation of synthesis of $\mathrm{BaTiO}_{3}$ by conventional solid-state reaction and oxalate coprecipitation route for piezoelectric applications. Ceramics International 2007, 33: 35-40.

[16] Wu L, Chure MCh, Wu KK, Chang WCh, Yang MJ, Liu WK, Wu MJ. Dielectric properties of barium titanate ceramics with different materials powder size. Ceramics International 2009, 35: 957-960.

[17] Dent AH, Patel A, Gutleber J, Tormey E, Sampath S, Herman H. High velocity oxy-fuel and plasma deposition of $\mathrm{BaTiO}_{3}$ and $(\mathrm{Ba}, \mathrm{Sr}) \mathrm{TiO}_{3}$. Materials Science and Engineering B 2001, 87: 23-30.

[18] Buchanan RC. Ceramic Materials for Electronics. $3^{\text {rd }}$ Ed. New York, USA: M. Dekker, 2004.

[19] Cheng H-F, Chen Y-Ch, Wang G, Xiang X-D, Chen G-Y, Liu K-S, Lin I-Nan. Study of second-phases in $\mathrm{Ba}(\mathrm{Mg} 1 / 3 \mathrm{Ta} 2 / 3) \mathrm{O} 3$ materials by microwave near-field microscopy. Journal of the European Ceramic Society 2003, 23: 2667-2670.

[20] Morey O, Goeuriot P, Juve D, Treheux D. $J$ of the Eur Ceram Soc 2003, 23: 345-355

[21] Wang X, Zhang L, Liu H, Zhai J, Yao X. Dielectric nonlinear properties of $\mathrm{BaTiO}_{3}-\mathrm{CaTiO}_{3}-\mathrm{SrTiO}_{3}$ 
ceramics near the solubility limit. Materials Chemistry and Physics 2008, 112: 675-678.

[22] Ahn K, Wessels BW, Sampath S. Dielectric properties of plasma-spray-deposited $\mathrm{BaTiO}_{3}$ and $\mathrm{Ba}_{0.68} \mathrm{Sr}_{0.32} \mathrm{TiO}_{3}$ thick films. $J$ Mater Res 2003, 5: 1227-1231.

[23] Ferreira V M, Azough F, Freer R, and Baptista JL. The Effect of $\mathrm{Cr}$ and $\mathrm{La}$ on $\mathrm{MgTiO}_{3}$ and $\mathrm{MgTiO}_{3}-\mathrm{CaTiO}_{3}$ microwave dielectric ceramics. $J$ Mater Res1997, 12: 3293-3299.

[24] Zeng J, Wang H, Shang S, Wang Z, Lin C. Preparation of textured $\mathrm{Mg}_{2} \mathrm{TiO}_{4}$ thin films on $\mathrm{Si}$ substrate by atmospheric pressure metallorganic chemical vapour deposition. J Mater Sci Mater Electron 1997, 8: 159-162.

[25] Haefie H, Lang HP, Sum R, Guntherodt HJ, Berthold L, Hesse D. $\mathrm{Mg}_{2} \mathrm{TiO}_{4}$ as a novel substrate for high-temperature superconducting thin films. Appl Phys Lett 1992, 61: 9-19.

[26] Wing ZN, Halloran JW, Zhang Q, McGinn PJ. Variable dielectrics in the calcium magnesium titanate system characterized with scanning microwave microscopy. J Am Ceram Soc 2006, 89: 1610-1614.

[27] Lemanov VV, Sotnikov AV, Smirnova EP, Weihnacht M, Kunze R. Perovskite $\mathrm{CaTiO}_{3}$ as an incipient ferroelectric. Solid State Communications 1999, 110: 611-614.

[28] Sudheendran K, James Raju KC. Temperature dependent impedance and dielectric properties of
$0.7 \mathrm{CaTiO}_{3}-0.3 \mathrm{NdAlO}_{3}$ ceramics. Indian journal of engineering \& material sciences 2008, 15: 133-136.

[29] Bak W. Study of the relaxor behaviour in $\mathrm{Ba} 0.68 \mathrm{Na} 0.32 \mathrm{Ti0}$.68Nb0.32O3 ceramic. Journal of Achievements in Materials and Manufacturing Engineering 2009, 37: 24-27.

[30] Dervos CT, Thirios Ef, Novacovich J, Vassiliou P, Skafidas P. Permittivity properties of thermally treated $\mathrm{TiO}_{2}$. Materials Letters 2004, 58: 15021507.

[31] Hu P, Jiao H, Wang Ch-H, Wang X-M, Ye S, Jing $\mathrm{X}-\mathrm{P}$, Zhao $\mathrm{F}$, Yue Z-X. Influence of thermal treatments on the low frequency conductivity and microwave dielectric loss of $\mathrm{CaTiO}_{3}$ ceramics. Materials Science and Engineering B 2011, 176: 401-405.

[32] Ctibor P, Hrabovský M. Plasma sprayed $\mathrm{TiO}_{2}$ : The influence of power of an electric supply on particle parameters in the flight and character of sprayed coating. Journal of the European Ceramic Society 2010, 30: 3131-3136.

[33] Bak W, Starzyk F, Kajtoch C, Nogas-Cwikiel E. Elevated temperature induced dispersion phenomena in Ba1-xNaxTi1-xNbxO3. Archives of Materials Science and Engineering 2008, 29: 5-9.

[34] Ctibor P, Ageorges H, Sedlacek J, Ctvrtlik R. Structure and properties of plasma sprayed $\mathrm{BaTiO}_{3}$ coatings. Ceramics International 2010, 36: 2155-2162. 